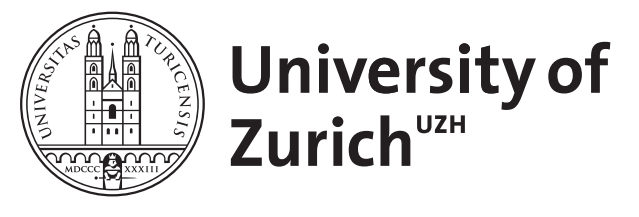

\title{
Recessions are bad for workplace safety
}

Boone, Jan ; van Ours, Jan C ; Wüllrich, Jean-Philippe ; Zweimüller, Josef

\begin{abstract}
Workplace accidents are an important economic phenomenon. Yet, the pro-cyclical fluctuations in workplace accidents are not well understood. They could be related to fluctuations in effort and working hours, but workplace accidents may also be affected by reporting behavior. Our paper uses unique data on workplace accidents from an Austrian matched worker-firm dataset to study in detail how economic incentives affect workplace accidents. We find that workers who reported an accident in a particular period of time are more likely to be fired later on. And, we find support for the idea that recessions influence the reporting of moderate workplace accidents: if workers think the probability of dismissals at the firm level is high, they are less likely to report a moderate workplace accident.
\end{abstract}

DOI: https://doi.org/10.1016/j.jhealeco.2011.05.013

Posted at the Zurich Open Repository and Archive, University of Zurich ZORA URL: https://doi.org/10.5167/uzh-50856

Journal Article

Originally published at:

Boone, Jan; van Ours, Jan C; Wüllrich, Jean-Philippe; Zweimüller, Josef (2011). Recessions are bad for workplace safety. Journal of Health Economics, 30(4):764-773.

DOI: https://doi.org/10.1016/j.jhealeco.2011.05.013 


\title{
Recessions Are Bad for Workplace Safety
}

\author{
Jan Boone \\ CentER, Tilburg University \\ and IZA \\ Jan C. van Ours \\ CentER, Tilburg University, \\ University of Melbourne, CESifo, CEPR and IZA \\ Jean-Philippe Wuellrich \\ University of Zurich \\ Josef Zweimüller \\ University of Zurich \\ and IZA
}

Discussion Paper No. 5688

May 2011

IZA

P.O. Box 7240

53072 Bonn

Germany

Phone: +49-228-3894-0

Fax: +49-228-3894-180

E-mail: iza@iza.org

\begin{abstract}
Any opinions expressed here are those of the author(s) and not those of IZA. Research published in this series may include views on policy, but the institute itself takes no institutional policy positions.

The Institute for the Study of Labor (IZA) in Bonn is a local and virtual international research center and a place of communication between science, politics and business. IZA is an independent nonprofit organization supported by Deutsche Post Foundation. The center is associated with the University of Bonn and offers a stimulating research environment through its international network, workshops and conferences, data service, project support, research visits and doctoral program. IZA engages in (i) original and internationally competitive research in all fields of labor economics, (ii) development of policy concepts, and (iii) dissemination of research results and concepts to the interested public.
\end{abstract}

IZA Discussion Papers often represent preliminary work and are circulated to encourage discussion. Citation of such a paper should account for its provisional character. A revised version may be available directly from the author. 
IZA Discussion Paper No. 5688

May 2011

\section{ABSTRACT \\ Recessions Are Bad for Workplace Safety ${ }^{*}$}

Workplace accidents are an important economic phenomenon. Yet, the pro-cyclical fluctuations in workplace accidents are not well understood. They could be related to fluctuations in effort and working hours, but workplace accidents may also be affected by reporting behavior. Our paper uses unique data on workplace accidents from an Austrian matched worker-firm dataset to study in detail how economic incentives affect workplace accidents. We find that workers who reported an accident in a particular period of time are more likely to be fired later on. And, we find support for the idea that recessions influence the reporting of moderate workplace accidents: if workers think the probability of dismissals at the firm level is high, they are less likely to report a moderate workplace accident.

JEL Classification: $\quad 110, \mathrm{~J} 60, \mathrm{~J} 81$

Keywords: workplace accidents, economic incentives, cyclical fluctuations

Corresponding author:

Jan C. van Ours

CentER

Tilburg University

P.O. Box 90153

5000 LE Tilburg

The Netherlands

E-mail: vanours@uvt.nl

\footnotetext{
* The authors thank two anonymous referees for helpful comments on a previous version of the paper.
} 


\section{Introduction}

Many workers face the risk of being involved in a workplace accident. ${ }^{1}$ For instance, in the EU-15 in 2004 there were around 4 million occupational accidents leading to more than 3 days' absence from work, which is equivalent to an accident rate of $3.2 \%$. The total number of accidents, including those which did not involve absence from work amounted to 6.4 million, equivalent to an accident rate of $5.3 \% .^{2}$ The incidence of fatal accidents was 3.8 per 100,000 workers. Finally, annually around 140 million working days are lost due to non-fatal accidents. The accidents at work are estimated to cause annually costs of 55 billion Euros in EU-15, mostly due to lost working time.

Workplace accidents seem to be related to workplace safety, but cyclical fluctuations in workplace accidents are puzzling from an economic point of view. There are only few studies that address this question. Kossoris (1938) is a very early reference to the procyclical pattern in accident rates. Fairris (1998) shows that in the U.S., manufacturing injury rates are pro-cyclical. Shea (1990) suggests that variables such as overtime, hiring and firing rates, the share of non-production workers, and the investment-to-capital ratio may affect the accident rate over the business cycle. If firms require more hours worked from employees in booms and less in recessions, then hours worked will be pro-cyclical and the accident rate (per worker) positively correlated with aggregate fluctuations in the economy.

It seems obvious that workplace accidents are pro-cyclical because effort and hours of work are negatively related to unemployment and high effort makes accidents more likely. ${ }^{3}$ However, Boone and Van Ours (2006) provide an alternative explanation related to

\footnotetext{
${ }^{1}$ According to the European Agency for Safety and Health at Work a workplace accident is defined as a "discrete occurrence in the course of work, which leads to physical or mental harm". A fatal accident is defined as an accident, which leads to the death of a victim within 1 year (after the day) of the accident. The statistical information presented here is from European Commission (2008).

${ }^{2}$ There is a wide variation in the seriousness of the workplace accidents. Of all accidents in 2004, for $37 \%$ of accidents there was no absence from work or only up to three days, for $30 \%$ the absence was more than three days but less than two weeks and for $29 \%$ the absence was between two weeks and three months. Finally, the remaining $4 \%$ of accidents concerned an absence of three months or more, or permanent partial or total disability.

${ }^{3}$ Ruhm (2000) finds a strong relationship between macroeconomic conditions and mortality, which he attributes to hazardous working conditions, the physical exertion of employment, and job-related stress
} 
reporting behavior. Their idea is that in times of high unemployment workers are reluctant to report workplace accidents because they fear - correctly or incorrectly - that employers will hold this against them. ${ }^{4}$ If they are fired in a recession, it will take them a long time to find a new job. Hence the worker prefers not to report an accident. One way to distinguish between the two explanations is to study cyclical fluctuations in fatal workplace accidents. If cycles in workplace safety drive the cycles in workplace accidents this should also be the case for fatal accidents, which are always reported. If reporting behavior of workers is relevant then fatal accidents should not be affected by the unemployment rate or changes in the unemployment rate. Using annual aggregate data from OECD countries Boone and Van Ours (2006) find that non-fatal workplace accidents are inversely related to the unemployment rate, while fatal accident rates do not seem to be related to labor market conditions, which suggests that workplace accidents are indeed influenced by reporting behavior.

Our paper studies cyclical fluctuations in workplace accidents using micro data. We have information on workplace accidents of male blue-collar workers from Austrian matched worker-firm data over the period 2000-2006. Our unique data allow us to investigate in great detail how economic incentives influence reporting of workplace accidents. We are able to provide direct tests of the relationships between workplace accidents and firing of workers. Because we have micro data rather than country-wide data we can test whether indeed - as suggested in Boone and Van Ours (2006) - a worker is more likely to be laid-off after experiencing a moderate accident. Furthermore, we are able to investigate directly whether the firing rate affects the occurrence - through reporting behavior - of workplace accidents. In Boone and Van Ours (2006) the investigation was limited to cross-national comparisons. They therefore could not directly test the mechanism by which workplace accidents affects reporting behavior. Using micro-data allows us to go one step further.

when job hours are extended during short-lasting economic expansions.

${ }^{4}$ OECD (1989) notes that among social and psychological factors which influence workplace accidents statistics that "workers may not report injuries because they fear loss of attendance bonuses, or other personal disadvantages, such as becoming prime candidates for redundancy". Brooker et al. (1997) finding that back pain claim rates go down as unemployment goes up mention as possible explanation for this phenomenon that individuals choose to under-report claims during recessionary periods because they fear losing their jobs. 
Our new empirical results also allow us to develop a richer theoretical model with more interesting welfare analysis and policy implications.

The paper is set up as follows. In Section 2 we present a theoretical model that explains the accident reporting behavior of individual workers. Workers are heterogeneous with respect to accident proneness and an accident reveals the innate probability of a worker to experience an accident. Workers report accidents because once reported firms invest in prevention. We show that workers become less eager to report accidents the higher the probability that the firm needs to fire a worker because then it may be more profitable for a firm to fire the worker rather than invest in prevention. We also show that more serious accidents are more often reported because the prevention of such accidents is more important for a worker. Section 3 describes the data on workplace accidents from our Austrian dataset. Section 4 discusses the statistical model and presents estimation results. We find that workers who reported an accident in a particular period of time are more likely to be fired later on. Apparently, when deciding about whom to fire in case of a negative demand shock employers take the accident history of workers into account. And, we find support for the idea that recessions have a disciplinary effect concerning the reporting of workplace accidents: if workers think the probability of dismissals at the firm level is high, they are less likely to report a moderate accident. For severe accidents we find no such effect. Section 5 concludes.

\section{Theory}

We introduce a model in which workers who experience a moderate work-related accident can decide whether to report such an accident or not. If a worker reports the accident, the firm will make an investment to accommodate the workplace that reduces the probability of an accident to this worker in the next period. To see more precisely what we have in mind, consider the example of a nurse working in a hospital. One of her tasks is to lift people out of bed and help them into their wheelchair. Using the correct lifting techniques this can be done without causing back problems. However, the patient may lose his balance causing the nurse to overstretch her back. As a result, the nurse may (or may not) hurt her back. Having observed this accident, the firm may decide that the nurse is no longer allowed to lift patients out of bed on her own but instead has to get help from a colleague 
(or the beds of her patients are fitted with a device that facilitates lifting them).

More generally, think of a firm that obeys the general safety regulation rules and implements all accident prevention investments that are profitable to do for everyone. Nevertheless the firm may be willing to incur an additional cost that accommodates the individual's workplace once the firm has got additional information on the worker's individual accident risk. Of course, such workplace accommodation measures will be profitable for accidentprone workers but may not be profitable for workers with a small (individual) accident risk.

The main difference of our model compared to the one of Boone and Van Ours (2006) is the following. In Boone and Van Ours (2006) reporting an accident leads to a compensation (that varies with the severity of the accident) to the worker. In the model below, reporting an accident leads to investments to prevent future accidents. This makes the welfare analysis more interesting. Whereas there can only be under-reporting of accidents in Boone and Van Ours (2006), in the model below there can also be over-reporting of accidents.

\section{$2.1 \quad$ Positive analysis}

Consider a two period model. In the first period, a firm has two workers. If an accident happens, a worker can report the accident by the end of the period. To simplify the exposition, assume that accidents are verifiable, once reported. Hence it does not make sense to report an accident that did not happen. At the end of the first period there is an (exogenous) probability $\delta$ that demand for the firm's products falls which forces firm is forced to fire one of the two employees. Once the firm knows whether a worker stays or not, it can decide on worker-specific accident-prevention measures.

We assume that workers differ in type $q \in[0,1]$ where $q$ denotes the innate probability of a worker to experience an accident. This probability $q$ is distributed with density (distribution) function $f(q)(F(q))$. Before an accident happens, neither the worker, nor the firm knows $q$, only the distribution of $q$. If an accident happens, the worker experiences (expected) damage $\alpha_{w}$ and the firm $\alpha_{f}$. We assume that the damage is independent of a worker's type. After the accident happened, the worker (but not the firm) learns $q$. The worker learns how likely he is to have a (similar) accident in the next period. While, after an accident, the worker's $q$ is not observable the firm, the firm updates its beliefs about 
the worker's $q^{5,6}$

The firm can invest $\gamma$ in worker specific prevention of the accident. After the investment, the probability that type $q$ is involved in an accident is denoted by $q_{\gamma} \leq q$ where we assume that

$$
\frac{d\left(q-q_{\gamma}\right)}{d q}>0
$$

The prevention technology leads to a bigger fall in the accident probability for more accident prone workers. Basically, there is more to gain for high $q$ workers. ${ }^{7}$ We assume that it is not profitable to invest in the accident prevention technology for every worker:

$$
E\left(q-q_{\gamma}\right) \alpha_{f} \lessgtr \gamma
$$

where $E(q)=\int q d F(q)$ denotes the (prior) expected probability of an accident.

Now consider the case where a worker has reported an accident. The posterior distribution is then given by

$$
f(q \mid A)=\frac{q f(q)}{\int_{0}^{1} t d F(t)}
$$

We assume that it is profitable to invest in prevention, once a worker has reported an accident:

$$
E\left(q-q_{\gamma} \mid A\right) \alpha_{f}>\gamma
$$

\footnotetext{
${ }^{5}$ Assuming that the worker learns $q$ (perfectly) simplifies notation. The important feature is that the worker's posterior distribution of $q$ is more informative than the firm's posterior.

${ }^{6}$ In fact, after the accident the firm would like to learn $q$. One way to screen workers on $q$ after the accident is to offer them a choice between receiving an amount of money ("bribe") or the firm investing in safety measures. To the best of our knowledge, offering such a choice to workers is illegal.

${ }^{7}$ To illustrate things, consider again the nurse in the hospital. The patient may lose his balance causing the nurse to overstretch her back with probability $\lambda$. Given that this situation arises, the nurse's has individual probability $\tilde{q}$ that she hurts her back, hence the ex-ante probability of an accident is $q=\lambda \tilde{q}$. After the accident the nurse knows whether her back is likely to be strained again in a similar future situation ( $\tilde{q}$ close to 1). Alternatively, she may have hurt herself at home the day before which weakened her back. Therefore, although she hurt her back in this incident she is unlikely to get hurt in a similar situation in the future. When the hospital decides that the nurse is no longer allowed to lift patients out of bed on her own but has to get help from a colleague, the probability of ending up in a hazardous situation is reduced from $\lambda$ to $\lambda_{\gamma}<\lambda$. Indeed we find that $d\left(\left(\lambda-\lambda_{\gamma}\right) \tilde{q}\right) / d \tilde{q}>0$ in this example.
} 
where $E(q \mid A)=\int q d F(q \mid A)$. In words, once a worker has reported an accident, the firm knows that the worker is accident prone and investment in prevention becomes profitable. This effect gives an incentive for a worker to report an accident (see below). Note that the firm makes its investment decision without knowing $q$ for the worker since $q$ is not revealed to the firm. We also assume that it is not profitable to replace a worker who has reported an accident in the first period. Let $C$ denote the firing and rehiring cost. It is assumed that, a worker who produces surplus $y$ and receives wage $w$, we always have

$$
y-w-\gamma-E\left(q_{\gamma} \mid A\right) \alpha_{f}>-C+y-w-E(q) \alpha_{f} .
$$

That is, investing $\gamma$ and reducing the probability of an accident is more profitable than investing search cost $C$ and employing a new worker who has an accident with expected probability $E(q)$.

If a worker loses the job, he or she receives $b<w$ as expected value of being unemployed. This consists of a probability of finding a new job in the next period ${ }^{8}$ and unemployment benefit if no other job is found. We assume that a worker prefers to stay in his job at the start of the first period:

$$
w-E(q) \alpha_{w}>b
$$

Similarly, every type $q$ prefers to stay in the second period, if the firm invests in prevention:

$$
w-q_{\gamma} \alpha_{w}>b
$$

for each type $q_{\gamma}$. In other words, no worker voluntarily quits after reporting an accident.

Now consider the worker's incentive to report an accident in the first period. On the one hand, reporting the accident has a potential benefit to the worker. If the accident is reported, it is optimal for the firm (equation (4)) to invest in workplace accommodation which reduces the accident probability for the worker from $q$ to $q_{\gamma}$. On the other hand, reporting the accident has also a potential cost. If the firm is hit by a negative demand shock (which happens with probability $\delta$ ), the firm is better off firing the worker. (If either

\footnotetext{
${ }^{8}$ To ease notation, we assume that the probability of having an accident in the next job -in case the worker is fired-does not depend on a worker's current $q$. That is, $q$ is specific to the worker-firm match.
} 
none or two workers reported an accident, the firm is indifferent in firing either employee. In that case, an employee is chosen with probability $\frac{1}{2} \cdot{ }^{9}$ )

Given that a worker is the only one who experienced an accident in the first period, his expected pay off from reporting is given by

$$
\delta b+(1-\delta)\left(w-q_{\gamma} \alpha_{w}\right)
$$

If the negative shock hits the firm, it will fire the worker who has reported the accident, save on the accommodation expenditure $\gamma$ and get a lower probability of future accidents for the remaining worker (as $E(q \mid A)>E(q)$ ). If the worker is fired, he receives $b<w$. If the worker does not report the accident, his pay off equals

$$
\frac{1}{2} \delta b+\left(1-\frac{1}{2} \delta\right)\left(w-q \alpha_{w}\right)
$$

Hence a worker reports if and only if the expression in equation (8) exceeds (9); which can be rewritten as

$$
\frac{1}{2} \delta q+(1-\delta)\left(q-q_{\gamma}\right)>\frac{1}{2} \frac{\delta(w-b)}{\alpha_{w}}
$$

Because of assumption (1), the left hand side is increasing in $q$. Hence there is a critical value $q^{*}$ such that the inequality is satisfied for all $q>q^{*}$. Thus the (ex-ante) probability that the worker reports an accident is $1-F\left(q^{*}\right)$.

We find the following result.

Proposition 1 As $\delta$ increases, the probability that an accident is reported falls. As $\alpha_{w}$ increases, it becomes more likely that an accident is reported. As $\alpha_{w}$ increases, the effect of $\delta$ on $q^{*}$ is reduced.

Proof of proposition 1 Let $q^{*}$ denote the value for $q$ where (10) holds with equality. Then it is routine to verify that

$$
\frac{d q^{*}}{d \delta}=\frac{\frac{w-b}{2 \alpha_{w}}-\frac{1}{2} q_{\gamma}^{*}+\frac{1}{2}\left(q^{*}-q_{\gamma}^{*}\right)}{\frac{1}{2} \delta+(1-\delta) \frac{d\left(q^{*}-q_{\gamma}^{*}\right)}{d q^{*}}}>0
$$

\footnotetext{
${ }^{9}$ Note that in the second (final) period it is immaterial whether a worker reports an accident or not. No further accidents can be prevented and there is no firing decision by the firm.
} 
where the inequality follows from equations (1), (7) and $q-q_{\gamma}>0$. If $\alpha_{w}$ increases, the right hand side of (10) falls and $q^{*}$ falls as well. Finally, an increase in $\alpha_{w}$ reduces $d q^{*} / d \delta$ in equation (11). Hence, $q^{*}$ is less dependent on $\delta$ as $\alpha_{w}$ increases.

Q.E.D.

The intuition is as follows. The higher the probability that the firm needs to fire a worker, the less eager workers become in reporting accidents. More serious accidents (higher $\alpha_{w}$ ) are more often reported, since the prevention of such accidents is more important for a worker. Finally, the reporting of more serious accidents is less dependent on the expectations about the firing rate $\delta$.

Notice that our simple model yields empirically testable predictions which will be analyzed in the empirical analysis below. In particular, we will not only investigate whether accident reporting increases in booms and decreases in regressions but we will also test whether the cyclicality in reporting behavior is different between moderate and severe workplace accidents.

\subsection{Welfare analysis}

We conclude the section by summarizing the normative implications of the model. There are two main imperfections that cause the equilibrium above to deviate from the socially optimal outcome. First, both the worker and the firm only consider their own payoffs not the sum of payoffs. To illustrate, equation (2) implies that it is not profitable for the firm to invest for every worker. However, if we have

$$
E\left(q-q_{\gamma}\right)\left(\alpha_{f}+\alpha_{w}\right)>\gamma
$$

it is socially desirable that such an investment is made (ex ante) for every worker. Second, after an accident the worker learns his own $q$ but cannot credibly reveal this to the employer. Hence the firm bases its investment decision on $f(q \mid A)$ while it is socially optimal to base this decision on $q$. Related to this, the decision to fire a worker (with probability $\delta$ ) after an accident should also be based on $q$ and not on the accident itself. If the worker has accident probability $q<E(q)$ the social planner prefers the workplace accommodating investment to firing the worker. However, when $q>E(q))$ even the social planner prefers to fire a worker rather than investing in prevention of a further accident.

In the model above, reporting an accident leads the firm to invest in worker-specific safety measures (if the worker is not fired). Hence for all $q>q^{*}$ (where $q^{*}$ solves equation 
(10) with equality) the firm invests. Given that a worker is not fired after being involved in an accident, for which values of $q$ is it socially optimal to invest?

Lemma 2 It is socially optimal to invest in safety measures for a worker with $q>q^{s}$ where $q^{s}$ is defined by

$$
\left(q^{s}-q_{\gamma}^{s}\right)=\frac{\gamma}{\alpha_{w}+\alpha_{f}}
$$

Since we assume that $q-q_{\gamma}$ is increasing in $q$, there is a unique value for $q^{s}$ that satisfies equation (13). For $q<q^{s}$ the gain in safety $\left(q^{s}-q_{\gamma}^{s}\right)\left(\alpha_{w}+\alpha_{f}\right)$ due to the investment is too small to cover the cost $\gamma$.

Proposition 3 Assume that the solution $q^{s}$ to equation (13) satisfies

$$
q^{s}<\frac{w-b}{\alpha_{w}}
$$

then there exists $\delta^{*} \in\langle 0,1\rangle$ such that for $\delta<\delta^{*}$ the firm over-invests in safety measures compared to the social optimum while for $\delta>\delta^{*}$ the firm under-invests.

Proof of proposition 3 First, consider $\delta=0$. Then equation (10) implies that each worker $q \in[0,1]$ reports his accident, inducing the firm to invest in safety. However, such investment is only optimal for $q>q^{s}>0$. Hence for low $\delta$ we have over-investment in safety measures. Second, consider $\delta=1$. Comparing equations (8) and (9), it follows that workers $q$ report who satisfy

$$
w-q \alpha_{w}<b
$$

That is, workers who prefer to be unemployed rather than to continue working without additional safety measures report their accident (and get fired with probability 1 ). If it is the case that

$$
w-q^{s} \alpha_{w}>b
$$

type $q^{s}$ does not report in equilibrium while this would be socially optimal. Hence under the assumption made in the proposition, there is under-reporting and hence under-investment for $\delta$ close to 1 . Finally, note that $q^{s}$ does not depend on $\delta$ while equation (11) implies that 
$q^{*}$ is increasing in $\delta$. Hence there exists $\delta^{*} \in\langle 0,1\rangle$ such that there is over(under)-investment for $\delta>(<) \delta^{*}$.

The intuition for this result is as follows. When the probability of being fired is small, workers report each accident thereby inducing the firm to invest even though they know their probability of having another accident $q$ is actually quite low. However, for $\delta$ close to zero, there are no costs for the worker of doing this (probability of being fired is close to zero) and the firm bases its decision on the posterior distribution (3) not on the realization of $q$.

When the probability of being fired is high, workers do not report even though they learned that the probability of an accident $q$ and therefore the gain from prevention $q-q_{\gamma}$ is high. In this case, the firm does not invest even though such investment would be socially optimal. The interpretation of this result is as follows. Recessions are bad for workplace safety in the sense that they lead to under-reporting of accidents and therefore to underinvestment in prevention. In booms there is over-investment in workplace safety. Thus booms are "too good" for workplace safety. Accident-prevention investments are made that are wasteful from a social point of view but beneficial for workers.

If the government feels that generally speaking there is underinvestment in accident prevention, one policy option is to impede the discrimination in firing of workers who reported an accident. This gives firms a commitment device not to fire an employee in response to an accident report, thereby raising employees' incentive to report accidents. Given equation (12), this increases the bilateral surplus for the firm and the worker. One way in which this additional surplus can be shared is that the firm lowers the wage which the worker accepts as she now works in a safer workplace. At first sight, one may argue that the government does not need to intervene if this commitment is profitable to the firm. However, if the worker (but not the firm) knows how accident-prone he or she is (at the time of the hiring), firms that unilaterally introduce this commitment will tend to attract accident prone workers. This makes the unilateral introduction of this commitment unprofitable. Hence government action is called for that commits all firms not to fire workers that reported an accident with a higher probability. 


\section{Firing rates and the incidence of reported workplace ac- cidents}

\subsection{Background}

Our data are from the Austrian Social Insurance for Occupational Risks (AUVA) which covers all employees except federal railway employees and civil servants (2.8 million). The AUVA defines an occupational accident as "an unexpected external event causing injury, in locational, temporal and causal relationship to the insured occupation". ${ }^{10}$ By law, occupational accidents, due to which an insured person is more than 3 days incapable of working - including fatal accidents - are required to be reported within 5 days. In 2007, roughly 110,000 occupational accidents were reported. In case of an occupational accident the employer is legally obligated to continued remuneration of the victim for 8-10 weeks, depending on the job tenure of the worker. The cost of the curative treatment associated with the occupational accident is covered by the AUVA (the 2007 budget amounted to $€$ 950 million).

\subsection{Data}

The mandatory nature of the accident insurance implies that the AUVA keeps track of all reported workplace accidents. The data available to us covers workplace accidents that were reported between 2000 and 2006. ${ }^{11}$ In addition to the exact accident date, the AUVA data contains detailed information on the severity of accidents along four dimensions: (i) the number of inpatient care days, (ii) the number of days absent from work (excluding inpatient care days), (iii) whether the accident caused a reduction in the ability to work (i.e. whether the victim receives a (partial) disability pension as a result of the accident), and (iv) whether the accident is fatal. Moreover, it includes some information on the firm

\footnotetext{
${ }^{10}$ Activities in connection with the insured occupation, e.g. commuting to and from the workplace are covered by this insurance as well.

${ }^{11}$ More precisely, the data contains all workplace accidents of which the corresponding claims were recognized in 2000-2007. There is a time lag between reporting and recognition of accidents. For example, $93.0 \%$ of claims in 2000, were recognized in the same year and another $6.6 \%$ in the subsequent year. So, almost all claims are dealt within the same or the subsequent year. Because of this we ignore the workplace accidents that occurred in 2007 , because for this year the records may be incomplete.
} 
(such as industry affiliation) and the worker (such as whether a worker holds a blue- or white-collar occupation).

The unique feature of our dataset consists of a personal identifier which allows us to match the workplace accidents to individual data from the Austrian Social Security Database (ASSD, see Zweimüller et al. 2009 for details). The ASSD contains detailed information on individuals' employment status and earnings on a daily basis. It also contains some information on the employer, like regional location, industry affiliation, and a firm identifier. This enables us not only to derive the employment history of each individual, but also to characterize every single firm at each reference date in terms of its firm size, employment flows, and mean characteristics of their employees. ${ }^{12}$

Workplace accidents are a rare event which makes it difficult to study their interaction with firing rates. Therefore, we focus on a subset of Austrian workers and industries with relatively high accident rates, which, at the same time, is also important in terms of employment shares. We restrict our sample to male blue-collar workers aged 25-49 who are employed in manufacturing with at least 100 employees. In this sample, $97.8 \%$ of occupational accidents observed in the AUVA data could be matched to a corresponding employment record in the ASSD data. ${ }^{13}$ In the empirical analysis we work with longitudinal

\footnotetext{
${ }^{12}$ Note, however, that $3.4 \%$ workplace accidents cannot be matched unambiguously. This occurs when an individual holds more than one job. Workplace accidents for those individuals cannot be directly linked to an employer, since the AUVA data does not contain a firm identifier. We applied the following procedure in case of an unambiguous match: we matched the workplace accident to that employment spell, which was - based on information that is available in both data sets - the most likely. More precisely, we chose the most likely match by first ensuring consistency of the industry classification, second ensuring consistency of the type of employment (blue - vs. white-collar), and finally, if the match was still ambiguous, we simply chose the longest employment spell in question.

${ }^{13}$ The following figures highlight the high accident rates of our subgroup (all refer to the year 2000). Male workers were almost three times more likely involved in an accident than female workers (5.9 vs. 2.0 accidents per 100 workers); the number of accidents per 100 workers amounts to 7.0 among blue-collar workers and to only 1.6 among workers wearing a white-collar; the accident rate of prime-age workers (3.8 percent) is higher than for older workers (3.4); the manufacturing industry is faced with an accident rate of 6.0 percent - the second highest among all industries (compared to e.g. 4.8 percent in agriculture and forestry, 2.8 percent in retail, 2.6 percent in tourism, 4.3 in utilities, and 0.7 percent in banking and insurance; the accident rate in the construction sector is higher with 8.7 percent, but this sector is not adequate for our analysis due to its highly seasonal pattern in employment); and large firms are faced with 5.3 accidents per 100 workers while this number only amounts to 3.2 in small firms. The number
} 
data (monthly reference dates) containing individuals that are employed at the reference date. For this sample, a total of 64,080 workplace accidents are reported in the AUVA data during the period 2000-2006. ${ }^{14}$

\subsection{Definition of variables}

The two crucial variables for the empirical analysis are (i) a measure for the degree of severity of an occupational accident and (ii) a measure that captures the probability that demand for the firm's products falls. These variables are defined as follows. We distinguish two types of accidents, moderate and severe ones. This distinction should capture whether or not the reporting of an occupational accident is at discretion of the workers. In regard of this, we define an accident to be moderate if it simply results in a positive number of days absent from work (excluding inpatient care days). We define an occupational accident as severe otherwise, i.e. if it results in a positive number of inpatient care days, in a (partial) disability pension, or if it is fatal. This classification is a robust one for two reasons. First, it is implausible that severe accidents are over-reported, since a worker would have to fake an injury that brings him into hospital or one that makes him eligible to a partial disability pension. Second, severe accidents are very unlikely to be under-reported, since the experienced damage to the worker $\alpha_{w}$ is likely to be very high (high enough to end up in hospital or to suffer from a permanent reduction in work capacity). In contrast, our measure of moderate accidents is potentially subject to a reporting decision.

We define the measure for the probability that a firm will face a fall in demand for their products as the fraction of the workforce a firm lays off from $t-1$ to $t$. We therefore assume that the workers' best predictor at $t$ for the probability of an adverse demand shock

of accidents per 100 workers for our specific subgroup amounts to 10.7. The manufacturing industry has by far the biggest employment share accounting for 22 percent of total employment. Furthermore, male workers account for 55 percent of total employment and prime age workers for 66 percent. Bluecollar workers (workers in large firms) are with an employment share of 47 percent (46 percent) slightly underrepresented though. The employment share of our specific subgroup amounts to 4 percent with respect to total employment.

${ }^{14}$ A comparison of the situation in Austria with that in the U.S. shows that accident rates for manufacturing workers are lower in Austria than in the U.S. in the year 2000. While 7.8 accidents per 100 workers were reported in the U.S., only 6.0 were reported in Austria (the figure for the U.S. is taken from the Bureau of Labor Statistics). 
in $t+1$ is the firm's human resource planning (i.e. firing decisions) in $t$. We define "fired" as a worker who is employed in $t-1$ and either unemployed or out-of-labor force in $t .{ }^{15}$ Note that the firing rate is based on the entire workforce of each firm (i.e. including workers of all ages, white-collar workers, women, and industries other than manufacturing) and not on our restricted sample. Moreover, all regressions will additionally include a variable capturing the general business cycle measured by the monthly unemployment rate for male workers in manufacturing at the state level as well as calendar month and year dummies. However, our results also hold when we do not include aggregate business cycle indicators, so that firm firing rate reflects both idiosyncratic risk and the state of the aggregate business cycle.

\subsection{Descriptive statistics}

Table 1 provides general information about the accidents we observe in our sample. As shown our sample contains about 60,000 moderate workplace accidents and about 4,000 severe workplace accidents. On average a moderate accident causes a 12.5 days absenteeism, while for severe accidents this is 72.3 days. While for moderate accidents hardly anyone is absent for a long time, 27.2 percent of the workers who had a severe accident were absent for more than 3 months. More than half of the severe accidents lead to permanent disability. Commuting accidents are included in the registered accidents. Table 1 shows that 5.7 percent of all accidents are commuting-related. Among moderate accidents this number amounts to 5.3 percent and among severe accidents to 12.5 percent.

Table 2 provides summary statistics at the level of the individual worker and the level of the firm. The first column shows that our final data contains 9,263,282 individual-month observations (based on 205,170 workers who work in 1,256 different firms). Each worker has on average a risk of 0.7 percent to get involved in an occupational accident at each reference date, which is rather a low number. Considering the whole 2000-2006 period changes this picture. Almost one-third of all workers report at least one occupational accident over this period. Firms have a mean firing rate of 1.3 percent. The average unemployment rate in the manufacturing industry for male workers is 5.0 percent. The average worker can be

\footnotetext{
${ }^{15} \mathrm{~A}$ worker who is employed and then either moves to another firm or retires (old-age or disability-related) is not considered "fired".
} 
characterized as follows: he is aged 37.4 years, employed in the same firm since 9.2 years, has work experience of 18.1 years, was on sick leave for 0.3 percent in the last 2 years, and earns $€ 81.2$ a day. The second column of Table 2 provides companion information at the level of the firm (i.e. the average values of their workforce of male, blue-collar workers aged 25-49 years).

Table 2 about here

\section{Empirical analysis}

\subsection{Econometric model}

This section describes the empirical methodology. We focus on two main issues. First, our empirical analysis will address the question whether workers who report an accident are in fact exposed to a higher risk of subsequent job loss. Second, we empirically investigate, whether reported workplace accidents vary over the business cycle and how the cyclicality in reporting behavior differs between severe and more moderate workplace accidents. This second analysis forms the basis of our empirical investigation.

The following regression equation allows us to test whether workers who have recently reported an accident are those that are fired with a higher probability

$$
y_{i t+1}=\kappa \cdot \operatorname{pra}_{i t}+X_{i t}^{f \prime} \cdot \beta+\psi_{i}^{f}+\phi_{j(i) t}^{f}+\pi_{t}^{f}+\nu_{i t}
$$

where $y_{i+1 t}$ indicates whether or not a worker $i$ is fired in period $t+1$ as a function of current and past accidents that worker $i$ has reported at his current firm $j\left(\right.$ pra $\left._{i t}\right)$, control variables $X_{i t}^{f}$, worker fixed-effects $\left(\psi_{i}^{f}\right)$, firm fixed-effects $\left(\phi_{j(i) t}^{f}\right)$, and calendar month and year dummies $\left(\pi_{t}^{f}\right)$. The control variables $X_{i t}^{f}$ include a constant, the state unemployment rate for male, blue-collar workers, the sickness rate of the last 2 years of worker $i$ in firm $j$ (and its square), the daily wage (in logs), age (and its square), tenure (and its square), and experience (and its square). $\nu_{i t}$ is an error term satisfying the usual assumption which captures unobservable (to the researcher) factors influencing the reporting of occupational accidents. The prediction from our theoretical model is correct if the sign of $\kappa$ is positive.

The following regression equation studies the cyclical behavior of accident reporting

$$
a_{i t}=\delta \cdot f_{j(i), t}+X_{i t}^{a \prime} \cdot \beta+\psi_{i}^{a}+\phi_{j(i) t}^{a}+\pi_{t}^{a}+\epsilon_{i t},
$$


where $a_{i t}$ indicates whether individual $i$ reports an accident in $t, f_{j t}$ is the firing rate of firm $j$ at time $t, \psi_{i}^{a}$ are worker fixed-effects, $\phi_{j(i) t}^{a}$ are firm fixed-effects and $\pi_{t}^{a}$ represent calendar month and year dummies. The control variables $X_{i t}^{a}$ include a constant, the sickness rate of the last 2 years of worker $i$ in firm $j$ (and its square), the daily wage (in logs), age (and its square), tenure (and its square), and experience (and its square), and $\epsilon_{i t}$ is an error term satisfying the usual assumption which captures unobservable (to the researcher) factors influencing the reporting of occupational accidents. We estimate this regression equation separately for moderate and severe occupational accidents using all worker-month observations with a moderate occupational accident together with workermonths observations without any accident, and all worker-month observations with a severe occupational accident together with worker-months observations without any accident.

\subsection{Parameter estimates}

\subsubsection{Does reporting an accident increase the subsequent firing rate?}

We start our analysis by investigating whether the workers who reported an accident are exposed to a higher risk of job loss as compared to workers who did not report an accident. The existence of a significant impact of a previous accident on the risk of subsequent job loss is of obvious importance in the present context. Our theoretical reasoning builds upon the idea that an incentive not to report a workplace accidence arises exactly because accident reporting may increase the subsequent probability of getting fired. If the accident reporting behavior would be unrelated to the risk of job loss, the mechanism emphasized in this paper would not be relevant.

Table 3 shows the results of the impact of previous accident reporting (within the last twelve months) on the current probability of job loss. Columns (1)-(4) use the overall accident reporting during the last 12 months as the independent variable. Column (5) additionally allows for differential effects by the degree of severeness. It turns out that reporting any accident in the previous year, leads to a substantial increase in the probability of being laid off in the current month (column (1)). This effect is robust to the inclusion of worker fixed effects (column (2)), firm fixed effects (column (3)), and the inclusion of both worker as well as firm fixed effects (column (4)). Taking column (4) as our preferred specification (controlling for firm and worker characteristics that persist over time), the 
point estimate suggests that the firing probability is 0.15 percentage points higher for workers who have reported any accident within the last twelve months. This effect compares to an average firing rate of 0.75 percent in our sample. Hence we conclude that the impact of accident reporting on the risk of subsequent job loss is substantial, and equal to roughly 20 percent of the average firing rate in the sample. When we allow for differential impacts of moderate and severe accidents in Column (5) we see that the effect is mainly driven by moderate accidents whereas the impact of previous severe accidents is insignificant. The fact that severe accidents do not have an impact on subsequent job loss may seem surprising. However, this result is reconciled by the fact that workers who have a severe accident are more likely to benefit from higher job protection than those who have a moderate accident. ${ }^{16}$ In sum, our results strongly support the assumption made in section 2, that accident reporting behavior has a significant impact on the probability of being laid off later on.

Table 3 further shows that the unemployment rate has a significant effect on the individual probability to be fired. This effect is not surprising and represents a business cycle effect. If the economy is in a recession workers are more likely to lose their job. The impact is quantitatively important. A one percentage point increase in the contemporaneous unemployment rate leads to a 21 percent higher probability to be fired $(=[0.1589 / 100] / 0.0075))$. Moreover, we infer from Table 3 that a higher sickness rate within the last two years leads to a higher firing probability. This suggests that a similar mechanism as for accident rates may be at work for sickness rates. ${ }^{17}$

\footnotetext{
${ }^{16}$ In general, there is no particular job protection for those workers who are on sick leave due to an occupational accident (or illness) in Austria. However, if an accident leads to a permanent reduction in work capacity of 50 percent or more, an automatic process of acquiring the status of a disabled worker in the context of the Austrian Disabled Persons Employment Act (Behinderteneinstellungsgesetz) is launched. Once this process is launched, a worker has substantially increased job protection (dismissal is only valid if a special disability committee by the Austrian federal welfare office agrees to it). While moderate accidents do not lead to a permanent reduction in work capacity by construction, severe accidents do so in more than 50 percent of all instances (see Table 1). Thus, those workers who report a severe accidents are likely to be more strongly protected by legislation than those who report a moderate accident, which reconciles the puzzling result that there is no association between reporting a severe accident and being fired.

${ }^{17}$ See for example Barmby et al. (1994) who indicate that the effect of absence behavior on the probability of being fired may act as a worker discipline device.
} 
Table 3 about here

\subsubsection{Does accident reporting behavior vary over the business cycle?}

Our estimate of main interest concerns the cyclicality of accident reporting behavior. We report results of the effect of the firing rate on the probability to report an accident in table 4 where separate parameter estimates for moderate (Panel A) and severe (Panel B) accidents are presented. We report results on four different specifications that differ by the inclusion of worker and/or firm fixed effects. If neither worker nor firm fixed-effects are included (column (1)), then the effect of the firing rate on the probability of reporting a moderate accident is not significantly different from zero. When we include worker fixed effects, in contrast, we do find a significant negative effect. An increase of the firing rate by one standard deviation $(=0.0192$, see Table 2$)$ decreases the probability of reporting a moderate accident by 2.1 percent $(=[0.0192 \cdot(-0.0072)] / 0.0065)$. Apparently, adding worker fixed-effects (e.g. controlling for workers' ability to prevent a moderate workplace accident) is important. Put differently (and assuming that worker fixed effect are the only left-out confounders in column (1)), workers' time-invariant traits that reduce the probability of reporting a moderate workplace accident are negatively correlated with the firing rate. Column (3) replaces the worker fixed-effects by firm fixed-effects, which control inter alia for job safety measures provided by the employer. It turns out that the effect is now also significantly different from zero. This implies (assuming that the only left-out confounders are firm fixed effects in column (1)) that any workplace characteristics provided by the employer that reduce the probability of reporting moderate accidents by workers are negatively correlated with the firing rate. The results in column (2) and column (3) as compared to column (1) are in line with empirical findings in the compensating wage differential literature that more able workers sort into jobs with positive job characteristics (see e.g. Hwang et al. 1992). Column (4) includes worker as well as firm fixed effects, which is our preferred specification. Column (4) suggests that increasing the firing rate by one standard deviation leads to a 2.1 percent decrease in the probability to report a moderate accident. Notice further that all regressions in Table 4 control for the general business cycle (by including a dummy for each calendar year) as well as for seasonal effects (by including a dummy for each calendar month). Hence the estimated cyclical effects arise 
from idiosyncratic variations in the firing rates, holding the business cycle and seasonal effects constant. However, robustness checks show that removing year fixed effects to account for the business cycle does not affect our results (see below and the discussion paper version of our paper). The relationship between the firing rate and the reporting behavior of severe workplace accidents is investigated in Panel B of table 4 . We perform exactly the same regressions as we do for moderate workplace accidents. The results show that the firing rate does not have any statistically significant impact on workers' reporting behavior with respect to severe workplace accidents. This finding strongly supports our alternative explanation of the cyclical fluctuations in moderate workplace accident rates.

Table 4 about here

The larger a firm is the higher the risk that at least one occupational accident is reported, simply because they employ more workers. In addition, larger firms generally tend to have lower firing rates, which may suggest a mechanical interpretation for the negative relationship between the incidence of an accident and the expected firing rate. Therefore, we also performed an analysis at the level of the firm. ${ }^{18}$ Table 5 shows the parameter estimates. We also perform a sensitivity analysis with respect to the inclusion of firm fixed effects as already done in table 4 by presenting results without including firm fixed effects (column (1)) and with including firm fixed effects (column (2)). It turns out that the results based at the level of the firm are very much in line with the estimates based on individual data. In column (1) we again see that the firing rate is unrelated to the probability of reporting an moderate accident if firm fixed effects are not controlled for. Including firm fixed effects changes the picture. Column (2) shows that an increase in the firing rate by one standard deviation $(=0.0275$, see table 2$)$ reduces the probability that a firm faces at least one moderate workplace accident by 1.5 percent $(=[0.0275 \cdot(-0.2066)] / 0.3698)$. The probability that a firm faces at least one severe accident, in contrast, is unrelated to the firing rate. The analysis at the level of the firm thus strongly supports our findings derived at the level of the worker.

\footnotetext{
${ }^{18}$ The variation in the firing rate used in Table 4 is only at the level of the firm and we therefore presented standard errors adjusted for clustering on the firm in addition to those clustered on workers. Performing the analysis directly at the firm level is an alternative approach to account for this.
} 
Table 5 about here

To further investigate the robustness of our findings we also performed additional sensitivity analyses. First, we investigated the relevance of commuting accidents. As indicated in section 3.4, commuting accidents are substantially overrepresented among severe accidents. Our results are unaffected by this overrepresentation unless the reporting behavior between workplace and commuting accidents differs (e.g. if commuting accidents are always reported). To investigate this issue we excluded commuting-related accidents and re-estimated the impact of the expected firing rate on the reporting of accidents. As shown in Table 6, the results are very robust to the exclusion of commuting accidents suggesting that the reporting behavior between accidents during commuting and at the workplace does not differ. We conclude that the presence of commuting accidents does not change the interpretation of our results. Second, we investigated how sensitive our results are to the inclusion of year fixed effects in the estimates presented in table 4. Year fixed effects may absorb too much of the variation in the business cycle. As shown in Table 7, excluding year fixed effects from the estimates does not affect the relevant parameter estimates. This suggests that the firm-specific variation we use does indeed capture the macro-level variation we want. Finally, we checked whether our results are robust to the inclusion of all workers by treating severe accidents as non-accidents if moderate accidents are investigated (and vice versa). Table 8 shows that our results do not change if all workers are included in the analysis.

To sum up, our empirical findings are consistent with our theoretical predictions. Workers who report a workplace accident in the previous year are more likely to be laid off. This suggests that when deciding about whom to fire employers take the accident history of workers into account. We have also shown that while the probability of reporting a moderate accident is governed by firms' firing rate, this is not true for severe accidents. Recall that the distinction between moderate and severe workplace accidents reflects the extent to which the reporting of such an accident is at the discretion of the workers. The results suggest that the higher the firm's firing rate, the more reluctant their workers are to report a moderate workplace accident. We do not find such a pattern for severe workplace accidents. Hence, our findings are consistent with the idea that the reporting behavior is the driving force behind the pro-cyclicality of the incidence of workplace accidents. Our 
data do not allow to determine whether moderate workplace accidents are rather overreported in booms or under-reported in recessions. The results simply tell that moderate workplace accidents are relatively less reported in recessions. To the extent that our model captures the main aspect that drive workers' reporting decisions and firms' workplacesafety investment decisions our evidence is consistent with the idea that recessions are bad for workplace safety due to underinvestment in accident prevention.

\section{Conclusions}

Workplace accidents are related to workplace safety. Nevertheless, cyclical fluctuations in workplace accidents are puzzling from an economic point of view. Workplace accidents could be pro-cyclical because effort and hours of work are negatively related to unemployment and because higher work effort makes accidents more likely. Hence we should see more accidents during a boom and less during a recession. Alternatively, cyclical fluctuations in workplace accidents may be related to reporting behavior. In times of high unemployment workers are reluctant to report workplace accidents because they fear that employers will hold this against them. In this paper we investigate this alternative explanation using high-quality Austrian matched worker-firm data containing information about workplace accidents of blue-collar workers in manufacturing. We find that workers who reported an accident in particular period of time are more likely to be fired later on. Apparently, when deciding about whom to fire, employers take the accident history of workers into account. Moreover, we find support for the idea that recessions affect the reporting of workplace accidents: if the probability to be dismissed is high, workers are less likely to report a moderate accident. For severe accidents we do not find such an effect.

The cyclical sensitivity of the incidence of workplace accidents appears to be related to reporting behavior. As indicated in the theoretical part of the paper the cyclical fluctuations in reporting behavior has clear welfare implications as investments in prevention of workplace accidents may be suboptimal. If in recessions firing rates go up workers may underreport workplace accidents and thus firms under-invest in workplace safety. In booms workers may over-report workplace accidents and therefore firms over-invest in workplace safety, i.e. although workers benefit from the investments in workplace safety they are wasteful from a social point of view. 
In light of our theoretical analysis, our empirical evidence suggests that recessions are bad for workplace safety. From the point of view of economic policy, a way to bring the economy closer to the social optimum would be to introduce measures that impede the discrimination in firing against workers who reported an accident. This would increase the incentive of firms to invest in workplace safety also during recessions. 


\section{References}

[1] Barmby, T.A., J.G. Sessions and J.G. Treble (1994) Absenteeism, efficiency wages and shirking, Scandinavian Journal of Economics, 96, 561—566.

[2] Boone, J. and J.C. van Ours (2006) Are recessions good for workplace safety?, Journal of Health Economics, 25, 1069-1093.

[3] Brooker, A., J.W. Frank and V.S. Tarasuk (1997) Back pain claim rates and the business cycle, Social Science and Medicine, 45, 429-439.

[4] European Commission (2008) The Social Situation in the European Union 200\%, Eurostat.

[5] Fairris, D. (1998) Institutional change in shopfloor governance and the trajectory of postwar injury rates in U.S. manufacturing, 1946-1970, Industrial and Labor Relations Review, 51, 187-203.

[6] Hae-shin Hwang, W.R. Reed and C. Hubbard (1992) Compensating Wage Differentials and Unobserved Productivity, Journal of Political Economy, 100, 835-858.

[7] Johansson, P. and M. Palme (1996) Do economic incentives affect work absence? Empirical evidence using Swedish micro data, Journal of Public Economics, 59, 195218.

[8] Kossoris, M. (1938) Industrial injuries and the business cycle, Monthly Labor Review, $579-594$.

[9] Mortensen, D. and C. Pissarides (1999) New developments in models of search in the labor market, In Ashenfelter, O. and D. Card (Eds.), Handbook of Labor Economics, Amsterdam, North-Holland.

[10] Ruhm, C.J. (2000) Are recessions good for your health?, Quarterly Journal of Economics, 115, 617-650.

[11] Ruhm, C.J. (2001) Economic expansions are unhealthy, Working Paper, University of North Carolina. 
[12] Shea, J. (1990) Accidents rates, labor effort, and the business cycle, SSRI Working Paper 9028, University of Wisconsin, Madison.

[13] Zweimüller, J., R. Winter-Ebmer, R. Lalive, A. Kuhn, J-P Wuellrich, O. Ruf, and S. Büchi (2009) Austrian social security database. 
Table 1: Characteristics of accidents

\begin{tabular}{|c|c|c|c|}
\hline & All & Moderate & Severe \\
\hline \multicolumn{4}{|l|}{ Type of Accident (in \%) } \\
\hline Workplace & 94.3 & 94.7 & 87.5 \\
\hline Commuting & 5.7 & 5.3 & 12.5 \\
\hline \multicolumn{4}{|l|}{ Missed work days } \\
\hline Days absent & 16.1 & 12.5 & 72.3 \\
\hline Days at home & 15.4 & 12.5 & 59.8 \\
\hline Days at hospital & 0.7 & - & 12.5 \\
\hline \multicolumn{4}{|l|}{ Distribution (in \%) } \\
\hline 0 days absent & 19.5 & 20.6 & 3.1 \\
\hline 1-3 days absent & 5.2 & 5.0 & 8.6 \\
\hline $4-13$ days absent & 39.9 & 41.8 & 10.4 \\
\hline 14-90 days absent & 33.5 & 32.3 & 50.7 \\
\hline $91-\infty$ days absent & 1.9 & 0.3 & 27.2 \\
\hline \multicolumn{4}{|l|}{ Severity } \\
\hline Fatal (in \%) & 0.0 & - & 1.5 \\
\hline Permanent disability (in \%) & 3.1 & - & 51.5 \\
\hline
\end{tabular}

Source: Own Calculations, based on AUVA, ASSD, and BMWA 
Table 2: Summary statistics at the individual level and the firm level

\begin{tabular}{lcc}
\hline & Individual level & Firm level \\
\hline Accident in $t$ (yes / no) & 0.0069 & \\
& $(0.0829)$ & \\
Accident in 2000-2006 (yes / no) & 0.3293 & \\
& $(0.4700)$ & \\
\hline Moderate accident in t (yes / no) & & 0.3698 \\
& & $(0.4828)$ \\
Severe accident in t (yes / no) & 0.0411 \\
& & $(0.1985)$ \\
\hline Firing rate (from $t-1$ to $t$ ) & 0.0128 & 0.0153 \\
& $(0.0192)$ & $(0.0275)$ \\
Unemployment rate & 0.0504 & 0.0529 \\
& $(0.0281)$ & $(0.0306)$ \\
\hline Age & 37.3941 & 37.3478 \\
Tenure (in 10 years) & $(6.8500)$ & $(2.1379)$ \\
& 0.9221 & 0.8414 \\
Experience (in 10 years) & $(0.7194)$ & $(0.4264)$ \\
& 1.8069 & 1.7413 \\
Sickness rate (last 2 years) & $(0.7423)$ & $(0.3316)$ \\
& 0.0031 & 0.0028 \\
Daily wage (in $€$ ) & $(0.0207)$ & $(0.0048)$ \\
& 81.2243 & 74.6025 \\
Number of worker-month observations & $9,263,282$ & \\
Number of workers & 205,170 & \\
Number of firm-month observations & & 86,530 \\
& & 1,256 \\
\hline
\end{tabular}

Notes: (a) Standard deviation in parentheses. (b) Sample Selection workers: male, blue-collar workers, aged 25-49 years and employed in firms (manufacturing sector) with on average at least 100 employees over the sample period from 2000-2006. (c) Sample Selection firms: Firms (manufacturing sector) with on average at least 100 employees over the sample period from 2000-2006; all variables refer to the male, blue-collar workforce aged 25-49. (d) Source: Own Calculations, based on AUVA, ASSD, and BMWA 
Table 3: Regression results for testing the crucial model assumption

\begin{tabular}{|c|c|c|c|c|c|}
\hline \multirow{3}{*}{$\begin{array}{l}\text { Mean } \\
\text { Standard deviation }\end{array}$} & \multicolumn{5}{|c|}{ Dummy variable ( $=1$ if worker is laid off) } \\
\hline & & & $\begin{array}{l}0.0075 \\
0.0861\end{array}$ & & \\
\hline & $(1)$ & $(2)$ & $(3)$ & $(4)$ & $(5)$ \\
\hline $\begin{array}{l}\text { moderate accident } \\
\text { in } t \in[t-12, t-1]\end{array}$ & & & & & $\begin{array}{l}0.0016^{\star \star \star} \\
(0.0001)\end{array}$ \\
\hline $\begin{array}{l}\text { severe accident } \\
\text { in } t \in[t-12, t-1]\end{array}$ & & & & & $\begin{array}{c}0.0002 \\
(0.0006)\end{array}$ \\
\hline $\begin{array}{l}\text { any accident } \\
\text { in } t \in[t-12, t-1]\end{array}$ & $\begin{array}{l}0.0011^{\star \star \star} \\
(0.0001)\end{array}$ & $\begin{array}{l}0.0015^{\star \star \star} \\
(0.0001)\end{array}$ & $\begin{array}{l}0.0008^{\star \star \star} \\
(0.0001)\end{array}$ & $\begin{array}{l}0.0015^{\star \star \star} \\
(0.0001)\end{array}$ & \\
\hline unemployment rate & $\begin{array}{l}0.0189^{\star \star \star} \\
(0.0016)\end{array}$ & $\begin{array}{l}0.1386^{\star \star \star} \\
(0.0073)\end{array}$ & $\begin{array}{l}0.0833^{\star \star \star} \\
(0.0068)\end{array}$ & $\begin{array}{l}0.1589^{\star \star \star} \\
(0.0070)\end{array}$ & $\begin{array}{l}0.1589^{\star \star \star} \\
(0.0070)\end{array}$ \\
\hline sickness rate (last 2 years) & $\begin{array}{l}0.0778^{\star \star \star} \\
(0.0052)\end{array}$ & $\begin{array}{l}0.0436^{\star \star \star} \\
(0.0061)\end{array}$ & $\begin{array}{l}0.0637^{\star \star \star} \\
(0.0050)\end{array}$ & $\begin{array}{l}0.0413^{\star \star \star} \\
(0.0061)\end{array}$ & $\begin{array}{l}0.0419^{\star \star \star} \\
(0.0061)\end{array}$ \\
\hline sickness rate (last 2 years) ${ }^{2}$ & $\begin{array}{c}-0.0655^{\star \star \star} \\
(0.0188) \\
\end{array}$ & $\begin{array}{c}-0.0028 \\
(0.0232) \\
\end{array}$ & $\begin{array}{c}-0.0455^{\star \star} \\
(0.0185) \\
\end{array}$ & $\begin{array}{c}0.0016 \\
(0.0232) \\
\end{array}$ & $\begin{array}{c}0.0007 \\
(0.0232) \\
\end{array}$ \\
\hline Worker fixed-effects & No & Yes & No & Yes & Yes \\
\hline Firm fixed-effects & No & No & Yes & Yes & Yes \\
\hline $\mathrm{N}$ (worker-months obs.) & & & $7,883,354$ & & \\
\hline
\end{tabular}

Notes: (a) ${ }^{\star \star \star},{ }^{\star \star},{ }^{\star}$ denotes significance at the $1 \%, 5 \%$, and $10 \%$ level respectively. (b) All regressions (linear probability model) include the following control variables (not shown in the table): calendar month dummies, year dummies, age (and its square), tenure (and its square), experience (and its square), logarithm of daily wage (in $€)$. (c) Sample selection: male, blue-collar workers, aged 25-49 years and employed in firms (manufacturing sector) with on average at least 100 employees over the sample period from 2000-2006. (d) Robust standard errors in parentheses (adjusted for clustering on workers). (e) Sample is restricted to the years 2001-2006 due to the 1 year lag in workers' workplace accidents. (f) Source: Own Calculations, based on AUVA, ASSD, and BMWA. 
Table 4: Regression results of the impact of the firing rate on accident reporting (at individual level)

\section{Panel A: Moderate Workplace Accidents}

Dummy variable (= 1 if worker reports an accident)

\begin{tabular}{lcccc} 
Mean & \multicolumn{5}{c}{0.0065} \\
Standard deviation & $(1)$ & $(2)$ & $(3)$ & $(4)$ \\
\hline & 0.0006 & -0.0072 & -0.0084 & -0.0074 \\
\hline Firing rate (from $t-1$ to $t)$ & $(0.0016)$ & $(0.0017)^{\star \star \star}$ & $(0.0017)^{\star \star \star}$ & $(0.0017)^{\star \star \star}$ \\
& {$[0.0042]$} & {$[0.0018]^{\star \star \star}$} & {$[0.0021]^{\text {}}$} & {$[0.0019]^{\star \star \star}$} \\
\hline Worker fixed-effects & No & Yes & No & Yes \\
Firm fixed-effects & No & No & Yes & Yes \\
\hline \hline N (worker-months obs.) & \multicolumn{5}{c}{$9,259,374$} \\
\hline
\end{tabular}

\section{Panel B: Severe Workplace Accidents}

Dummy variable (= 1 if worker reports an accident)

\begin{tabular}{lcccc} 
Mean & \multicolumn{5}{c}{0.0004} \\
Standard deviation & $(1)$ & $(2)$ & $(3)$ & $(4)$ \\
\hline & 0.0008 & -0.0005 & -0.0003 & -0.0005 \\
Firing rate (from $t-1$ to $t)$ & $(0.0005)$ & $(0.0006)$ & $(0.0006)$ & $(0.0006)$ \\
& {$[0.0006]$} & {$[0.0007]$} & {$[0.0007]$} & {$[0.0007]$} \\
\hline Worker fixed-effects & No & Yes & No & Yes \\
Firm fixed-effects & No & No & Yes & Yes \\
\hline \hline N (worker-months obs.) & \multicolumn{5}{c}{$9,203,110$} \\
\hline
\end{tabular}

Notes: (a) ${ }^{\star \star \star},{ }^{\star \star},{ }^{\star}$ denotes significance at the $1 \%, 5 \%$, and $10 \%$ level respectively. (b) All regressions (linear probability model) include the following control variables: calendar month dummies, year dummies, age (and its square), tenure (and its square), experience (and its square), logarithm of daily wage (in $€$ ), sick leave rate in the previous two years (and its square). (c) Sample selection: male blue-collar workers, aged 25-49 years and employed at firms (manufacturing sector) with on average at least 100 employees over the sample period from 2000-2006. (d) Robust standard errors in parentheses (round brackets: adjusted for clustering on workers; squared brackets: adjusted for clustering on firms). (e) Source: Own Calculations, based on AUVA and ASSD. 
Table 5: Regression results of the impact of the firing rate on accident reporting (at firm level)

Panel A: Moderate Accidents

Dummy variable

$(=1$ if firm faces an accident)

\begin{tabular}{lcc} 
Mean & \multicolumn{2}{c}{0.3698} \\
Standard deviation & $(1)$ & 0.4828 \\
\hline & & $(2)$ \\
\hline Firing rate (from $t-1$ to $t)$ & -0.0212 & $-0.2066^{\star \star \star}$ \\
& $(0.0793)$ & $(0.0743)$ \\
\hline Firm fixed-effects & No & Yes \\
\hline \hline N (firm-months obs.) & & 86,530 \\
\hline
\end{tabular}

Panel B: Severe Accidents

\begin{tabular}{lcc} 
& \multicolumn{2}{c}{$\begin{array}{c}\text { Dummy variable } \\
\text { Mean }\end{array}$} \\
Standard deviation & \multicolumn{2}{c}{0.0411} \\
& \multicolumn{2}{c}{0.1985} \\
\hline Firing rate (from $t-1$ to $t)$ & $0.0515^{\star}$ & -0.0293 \\
& $(0.0288)$ & $(0.0322)$ \\
\hline Firm fixed-effects & No & Yes \\
\hline \hline N (firm-months obs.) & \multicolumn{2}{c}{86,530} \\
\hline
\end{tabular}

Notes: (a) ${ }^{\star \star \star},{ }^{\star \star},{ }^{\star}$ denotes significance at the $1 \%, 5 \%$, and $10 \%$ level respectively. (b) All regressions (linear probability model) include additionally the following control variables: calendar month dummies, year dummies, the number of male blue-collar workers aged 25-49 in the firm (in logs), and the firm average of employees' age (and its square), tenure (and its square), experience (and its square), logarithm of daily wage (in $€$ ) of this group of workers. (c) Sample selection: male, blue-collar workers, aged 25-49 years and employed in firms (manufacturing sector) with on average at least 100 employees over the sample period from 2000-2006. (d) Robust standard errors in parentheses (adjusted for clustering on firms). (e) Source: Own Calculations, based on AUVA and ASSD. 
Table 6: Regression results of the impact of the firing rate on accident reporting (at individual level); commuting accidents excluded

\section{Panel A: Moderate Workplace Accidents}

Dummy variable (= 1 if worker reports an accident)

\begin{tabular}{lcccc} 
Mean & \multicolumn{5}{c}{0.0062} \\
Standard deviation & $(1)$ & $(2)$ & $(3)$ & $(4)$ \\
\hline & 0.0013 & -0.0068 & -0.0081 & -0.0071 \\
\hline Firing rate (from $t-1$ to $t)$ & $(0.0016)$ & $(0.0016)^{\star \star \star}$ & $(0.0016)^{\star \star \star}$ & $(0.0017)^{\star \star \star}$ \\
& {$[0.0041]$} & {$[0.0017]^{\star \star \star}$} & {$[0.0020]^{\star \star \star}$} & {$[0.0018]^{\star \star \star}$} \\
\hline Worker fixed-effects & No & Yes & No & Yes \\
Firm fixed-effects & No & No & Yes & Yes \\
\hline \hline N (worker-months obs.) & \multicolumn{5}{c}{$9,259,864$} \\
\hline
\end{tabular}

\section{Panel B: Severe Workplace Accidents}

Dummy variable (= 1 if worker reports an accident)

\begin{tabular}{lcccc} 
Mean & \multicolumn{5}{c}{0.0004} \\
Standard deviation & $(1)$ & $(2)$ & $(3)$ & $(4)$ \\
\hline & 0.0009 & -0.0005 & -0.0003 & -0.0005 \\
Firing rate (from $t-1$ to $t)$ & $(0.0005)^{\star}$ & $(0.0006)$ & $(0.0006)$ & $(0.0006)$ \\
& {$[0.0006]$} & {$[0.0006]$} & {$[0.0006]$} & {$[0.0007]$} \\
\hline Worker fixed-effects & No & Yes & No & Yes \\
Firm fixed-effects & No & No & Yes & Yes \\
\hline \hline N (worker-months obs.) & \multicolumn{5}{c}{$9,206,285$} \\
\hline
\end{tabular}

Notes: (a) ${ }^{\star \star \star},{ }^{\star \star},{ }^{\star}$ denotes significance at the $1 \%, 5 \%$, and $10 \%$ level respectively. (b) All regressions (linear probability model) include the following control variables: calendar month dummies, year dummies, age (and its square), tenure (and its square), experience (and its square), logarithm of daily wage (in $€$ ), sick leave rate in the previous two years (and its square). (c) Sample selection: male blue-collar workers, aged 25-49 years and employed at firms (manufacturing sector) with on average at least 100 employees over the sample period from 2000-2006. (d) Robust standard errors in parentheses (round brackets: adjusted for clustering on workers; squared brackets: adjusted for clustering on firms). (e) Source: Own Calculations, based on AUVA and ASSD. 
Table 7: Regression results of the impact of the firing rate on accident reporting (at individual level): no year fixed effects

\section{Panel A: Moderate Workplace Accidents}

Dummy variable (= 1 if worker reports an accident)

\begin{tabular}{lcccc} 
Mean & \multicolumn{5}{c}{0.0065} \\
Standard deviation & $(1)$ & $(2)$ & $(3)$ & $(4)$ \\
\hline & 0.0014 & -0.0072 & -0.0074 & -0.0074 \\
\hline Firing rate (from $t-1$ to $t)$ & $(0.0016)$ & $(0.0017)^{\star \star \star}$ & $(0.0017)^{\star \star \star}$ & $(0.0017)^{\star \star \star}$ \\
& {$[0.0042]$} & {$[0.0018]^{\star \star \star}$} & {$[0.0021]^{\text {}}$} & {$[0.0019]^{\star \star \star}$} \\
\hline Worker fixed-effects & No & Yes & No & Yes \\
Firm fixed-effects & No & No & Yes & Yes \\
\hline \hline N (worker-months obs.) & \multicolumn{5}{c}{$9,259,374$} \\
\hline
\end{tabular}

\section{Panel B: Severe Workplace Accidents}

Dummy variable (= 1 if worker reports an accident)

\begin{tabular}{lcccc} 
Mean & \multicolumn{5}{c}{0.0004} \\
Standard deviation & $(1)$ & $(2)$ & $(3)$ & $(4)$ \\
\hline & 0.0008 & -0.0006 & -0.0004 & -0.0005 \\
Firing rate (from $t-1$ to $t)$ & $(0.0005)$ & $(0.0005)$ & $(0.0006)$ & $(0.0005)$ \\
& {$[0.0006]$} & {$[0.0007]$} & {$[0.0007]$} & {$[0.0007]$} \\
\hline Worker fixed-effects & No & Yes & No & Yes \\
Firm fixed-effects & No & No & Yes & Yes \\
\hline \hline N (worker-months obs.) & \multicolumn{5}{c}{$9,203,110$} \\
\hline
\end{tabular}

Notes: (a) ${ }^{\star \star \star},{ }^{\star \star},{ }^{\star}$ denotes significance at the $1 \%, 5 \%$, and $10 \%$ level respectively. (b) All regressions (linear probability model) include the following control variables: calendar month dummies, age (and its square), tenure (and its square), experience (and its square), logarithm of daily wage (in €), sick leave rate in the previous two years (and its square). (c) Sample selection: male blue-collar workers, aged 25-49 years and employed at firms (manufacturing sector) with on average at least 100 employees over the sample period from 2000-2006. (d) Robust standard errors in parentheses (round brackets: adjusted for clustering on workers; squared brackets: adjusted for clustering on firms). (e) Source: Own Calculations, based on AUVA and ASSD. 
Table 8: Regression results of the impact of the firing rate on accident reporting (at individual level); no observations dropped

\section{Panel A: Moderate Workplace Accidents}

Dummy variable (= 1 if worker reports an accident)

\begin{tabular}{lcccc} 
Mean & \multicolumn{5}{c}{0.0065} \\
Standard deviation & $(1)$ & $(2)$ & $(3)$ & $(4)$ \\
\hline & 0.0006 & -0.0072 & -0.0084 & -0.0074 \\
\hline Firing rate (from $t-1$ to $t)$ & $(0.0016)$ & $(0.0017)^{\star \star \star}$ & $(0.0017)^{\star \star \star}$ & $(0.0017)^{\star \star \star}$ \\
& {$[0.0042]$} & {$[0.0018]^{\star \star \star}$} & {$[0.0021]^{\text {}}$} & {$[0.0019]^{\star \star \star}$} \\
\hline Worker fixed-effects & No & Yes & No & Yes \\
Firm fixed-effects & No & No & Yes & Yes \\
\hline \hline N (worker-months obs.) & \multicolumn{5}{c}{$9,263,282$} \\
\hline
\end{tabular}

\section{Panel B: Severe Workplace Accidents}

Dummy variable (= 1 if worker reports an accident)

\begin{tabular}{lcrrc} 
Mean & \multicolumn{5}{c}{0.0004} \\
Standard deviation & $(1)$ & $(2)$ & $(3)$ & $(4)$ \\
\hline \multirow{2}{*}{ Firing rate (from $t-1$ to $t)$} & 0.0008 & -0.0005 & -0.0003 & -0.0004 \\
& $(0.0005)$ & $(0.0006)$ & $(0.0006)$ & $(0.0006)$ \\
& {$[0.0006]$} & {$[0.0006]$} & {$[0.0007]$} & {$[0.0007]$} \\
\hline Worker fixed-effects & No & Yes & No & Yes \\
Firm fixed-effects & No & No & Yes & Yes \\
\hline \hline N (worker-months obs.) & \multicolumn{5}{c}{$9,263,282$} \\
\hline
\end{tabular}

Notes: (a) ${ }^{\star \star \star},{ }^{\star \star},{ }^{\star}$ denotes significance at the $1 \%, 5 \%$, and $10 \%$ level respectively. (b) All regressions (linear probability model) include the following control variables: calendar month dummies, age (and its square), tenure (and its square), experience (and its square), logarithm of daily wage (in €), sick leave rate in the previous two years (and its square). (c) Sample selection: male blue-collar workers, aged 25-49 years and employed at firms (manufacturing sector) with on average at least 100 employees over the sample period from 2000-2006. (d) Robust standard errors in parentheses (round brackets: adjusted for clustering on workers; squared brackets: adjusted for clustering on firms). (e) Source: Own Calculations, based on AUVA and ASSD. 